\title{
Proyectos de Títulos carrera de Arquitectura. Período primavera 2007
}

Junto con presentar los siguientes proyectos de título, que han obtenido las mejores calificaciones en el semestre de primavera de 2007, entregamos un breve análisis estadístico, en forma de infografía, con el fin de dar a conocer los antecedentes disponibles en la Dirección de Escuela, sobre distintos temas de interés:

- la estructura temática de los Proyectos de Títulos para aportar una visión sobre las preferencias que están orientando la selección de éstos por parte de los alumnos, el cuerpo docente y la Facultad en general. Desde ese punto de vista, se estima que el interés de los resultados de este análisis radica en el supuesto que los contenidos curriculares del Plan de Estudios, de alguna manera se relacionan con las decisiones sobre los temas de proyectos, de donde el conocimiento de estos antecedentes colaboraría a dejar de manifiesto, tanto las áreas que concentran las mayores preferencias, como aquellas de menor presencia o aún ausentes del interés de los alumnos, lo que puede motivar alguna reflexión sobre la necesidad de fortalecer ciertas áreas de la investigación y la docencia en función de los objetivos de la carrera ${ }^{1}$

- Relacionado al tema, el tipo de mandante (público o privado) para cada proyecto creemos es información respecto a la tendencia nacional del tipo de proyecto, demostrando en este caso que gran parte de éstos siguen estando enfocados hacia el sector público.

- También relacionado al tema se entrega información respecto a la ubicación geográfica de los proyectos y si éstos se insertan en áreas urbanas o rurales. La tendencia es clara en este aspecto, la cantidad de proyectos desarrollados en la

Jaime Daroch, Informe de Proyectos de Títulos. Carrera de Arquitectura. Período 2002-2004.
Zona Central de Chile y en áreas urbanas es muchísimo mayor.

- La repartición por género del estudiantado que se titula nos entrega un índice interesante de comparar a nivel nacional y de evolución en el tiempo además de la comparación entre la variación por género entre la etapa de ingreso a la carrera y la de término de ésta.

Siendo la Universidad de Chile la más grande y heterogénea del país nos parece que estos cinco temas señalados anteriormente son un indicador de interés nacional que permite la comparación entre universidades y la comparación en determinados períodos de tiempo. Los dos siguientes temas analizados responden a información relevante a nivel de Facultad, permite conocer de cada generación su desempeño académico e información sobre el cuerpo docente:
- La calificación obtenida nos entrega información sobre el promedio de la generación y sirve de referencia para comparaciones anuales y temporales en general, además de su relación con los Planes de Estudio y estructuración de la Facultad como se ha señalado anteriormente.

- Otro indicador interesante a nivel de Facultad es la información referida a los profesores guía donde se repiten ciertas tendencias, se constata la inexistencia de profesoras en esta etapa docente y se corrobora la importancia de la exposición del programa de título de cada profesor a los estudiantes en la etapa de selección de profesor.

Entregamos esta información en forma gráfica para ser fácilmente interpretada.

\section{CUADRO RESUMEN PROYECTOS POR PROFESOR GUÍA 2007}

\begin{tabular}{lc|lc} 
Áreas & $N^{\circ}$ de Proyectos & Áreas & $N^{\circ}$ de Proyectos \\
\hline Amaya & 3 & Montealegre & 7 \\
\hline Besancon & 7 & Morelli & 5 \\
\hline Cárdenas & 5 & Munizaga & 3 \\
\hline Eliash & 10 & Pinto & 2 \\
\hline Gil & 2 & Prat & 7 \\
\hline Iglesis & 5 & Sartori & 1 \\
\hline Lyon & 9 & Soffia & 1 \\
\hline Marcino & 2 & Weil & 1 \\
\hline
\end{tabular}

Total proyectos 70

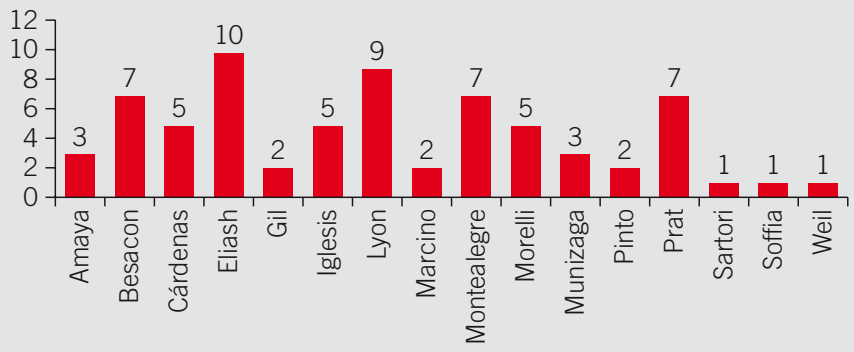

$\mathrm{N}^{\circ}$ de Proyectos 
CUADRO RESUMEN PROYECTOS POR ÁREAS TEMÁTICAS 2007

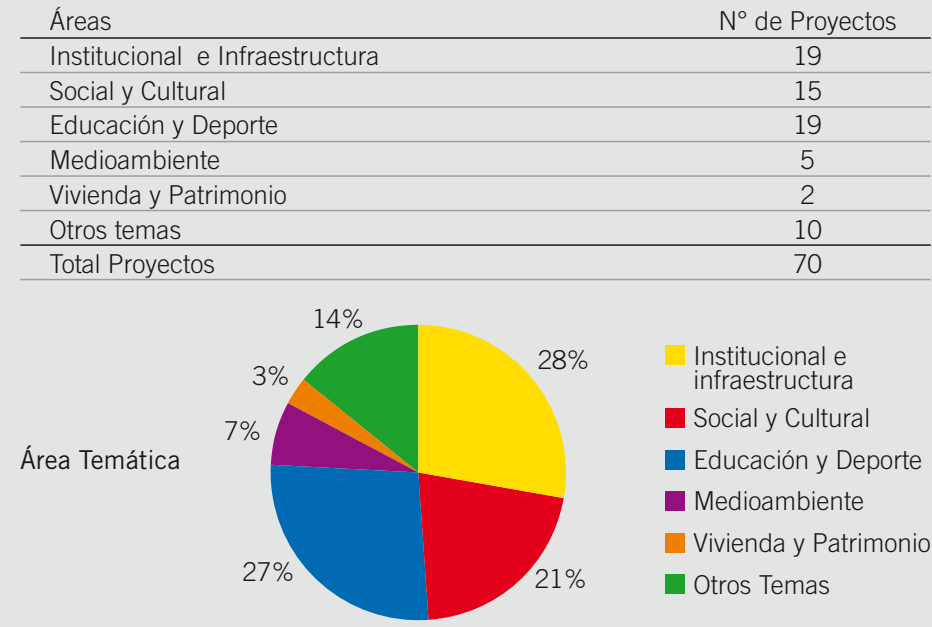

CUADRO RESUMEN PROYECTOS POR NOTA

\begin{tabular}{lc} 
Áreas & $N^{\circ}$ de Proyectos \\
\hline Reprobado & 3 \\
$4.0-4.9$ & 24 \\
\hline $5.0-5.9$ & 26 \\
\hline $6.0-6.9$ & 13 \\
\hline 7.0 & 4 \\
\hline Total Proyectos & 70 \\
\hline
\end{tabular}

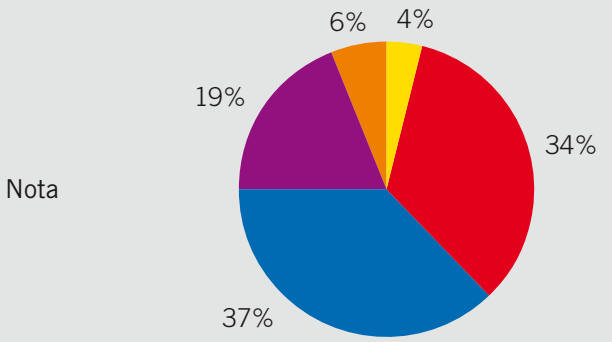

Reprobado

4,0 - 4,9

$5,0-5,9$

$6,0-6,9$

7,0

CUADRO RESUMEN PROYECTOS POR TIPO ASENTAMIENTO

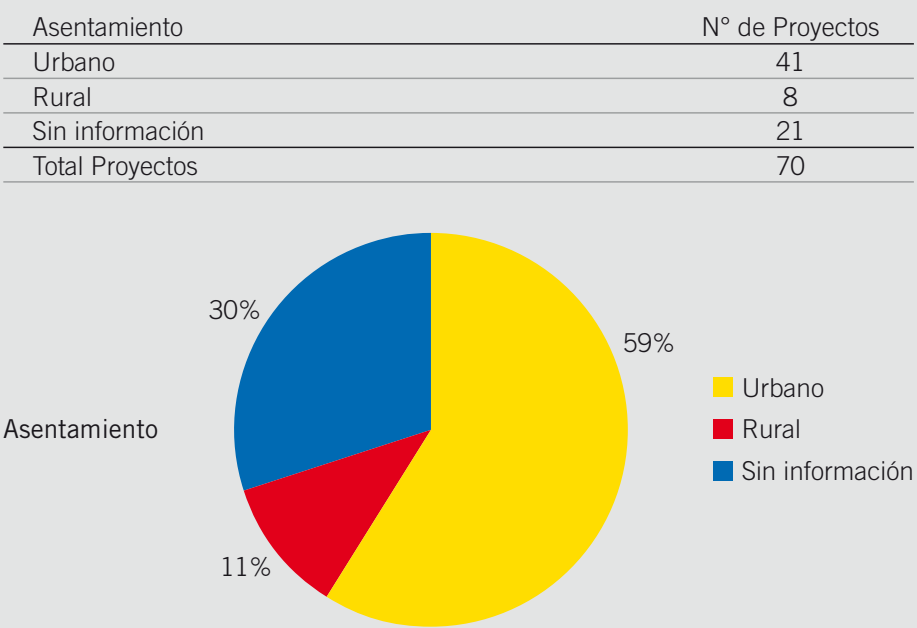

CUADRO RESUMEN PROYECTOS POR GÉNERO

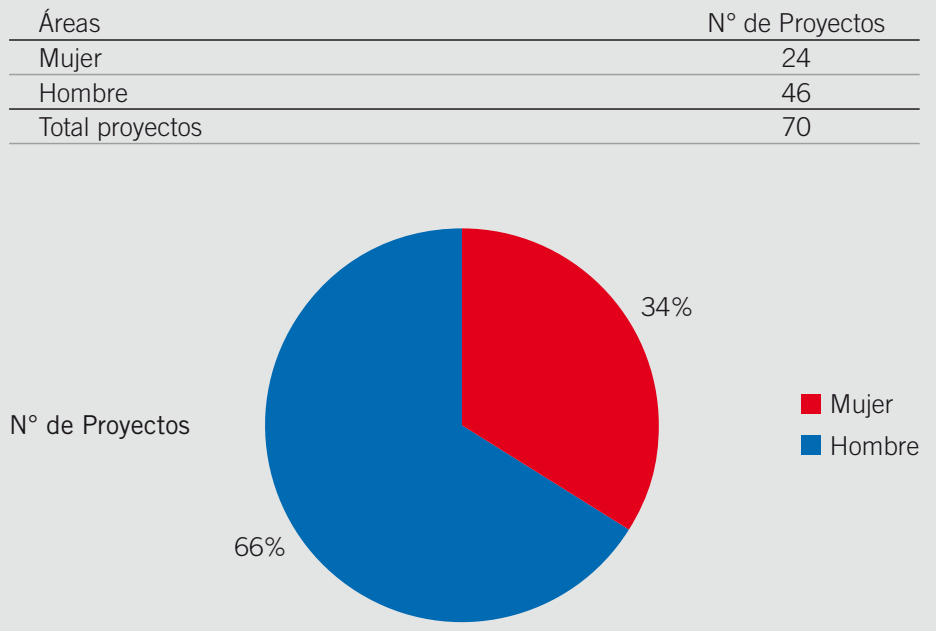

CUADRO RESUMEN PROYECTOS POR SECTOR MANDANTE 2007

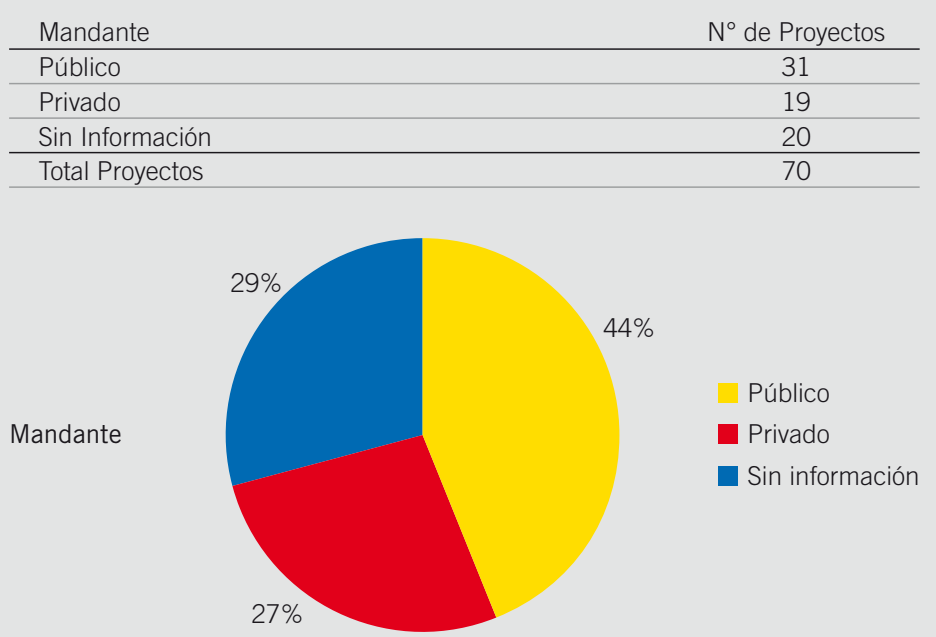

CUADRO RESUMEN PROYECTOS POR UBICACIÓN GEOGRÁFICA 2007

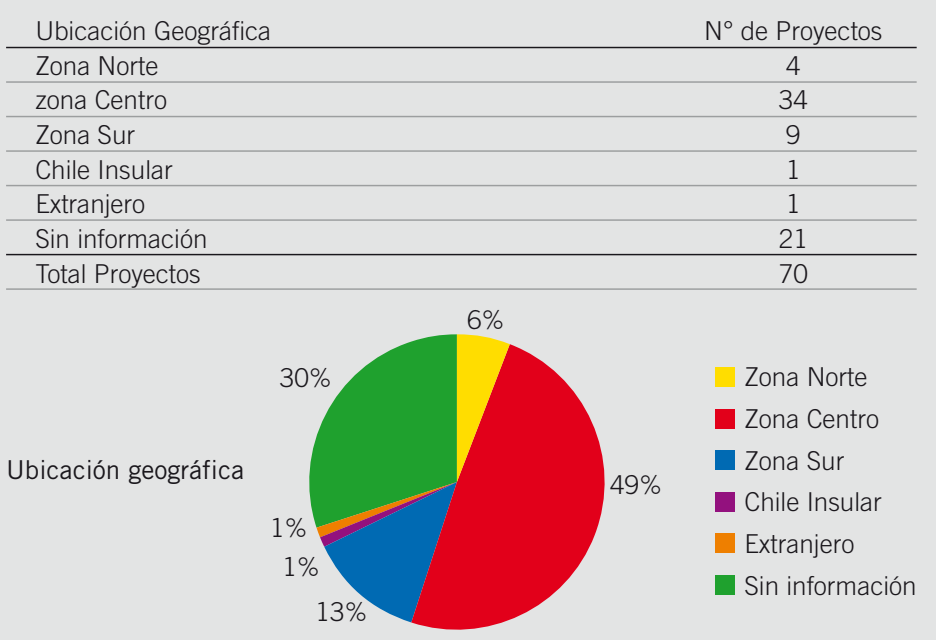




\section{CENTRO CULTURAL INDIA}
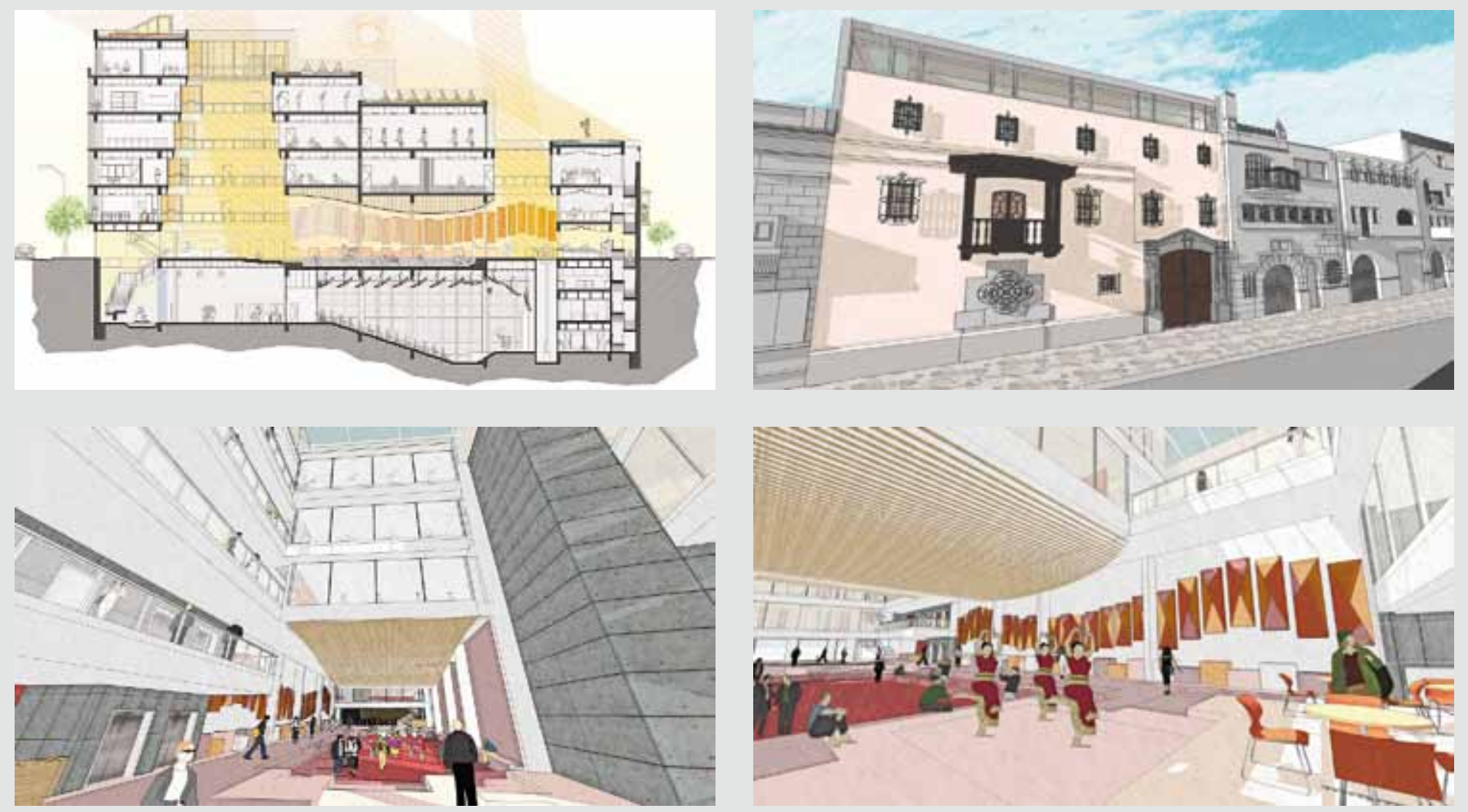

PREETI BELLANI V.

Profesor Guía: Alberto Montealegre K.

Objetivos y programa

El Centro Cultural India surge a partir de la necesidad de crear instalaciones para materializar la labor de difusión y cooperación cultural entre Chile e India, producto de la creciente relación económica, posicionando a nuestro país como puerta cultural de India a nivel sudamericano.

Basado en los distintos centros indios en el mundo, se propone la creación de recintos especialmente acondicionados para el yoga, la danza clásica, enseñanza musical y clases de literatura e idioma, artes escénicas, muestra cinematográfica y gastronomía, entre otros.

Emplazamiento

El proyecto se localiza en el Barrio Parque Forestal, ubicándose en uno de los sectores más consolidados de la ciudad. Además de la gran importancia cultural y conectividad del sector, su emplazamiento permite establecer una relación de cercanía con uno de los sectores de mayor concentración de instituto culturales extranjeros.
Condicionantes y propuesta urbana

Actualmente el terreno escogido para el proyecto posee salida hacia dos calles y se encuentra en una situación de medianería, ubicándose dentro de una manzana con alto valor histórico. A su vez, el predio se constituye como remate de un pasaje de casas coloniales actualmente en profundo estado de deterioro.

Es así como, con el fin de recuperar y vincular este pasaje colonial con la franja del Parque Forestal, se plantea la creación de un portal en la fachada norte del edificio que permite un traspaso libre de peatones a nivel de primer piso y otorga un acceso más amplio hacia el centro cultural.

Propuesta conceptual y espacial

En función de reafirmar la identidad y presencia de la cultura India la configuración de proyecto se basa en dos de los ejemplos más representativos de arquitectura tradicional en la India: el Haveli como tipología arquitectónica clásica india y el Kund como espacio público de intercambio cultural por excelencia.

Volumétricamente, esto se traduce en un ordenamiento por estratos de difusión, que conforman volúmenes de programa elevados del nivel de calle, separados entre sí mediante vacios, permitiendo la iluminación y relación visual entre todos los recintos. Esto da pie a un primer piso libre y traspasable desde sus dos fachadas, donde se encuentra el Kund: Plataforma de celebración de actividades masivas, muy comunes y frecuentes en la India.

Bajo el nivel de la calle se concentran todas las actividades de difusión que requieren un nivel de iluminación menor (auditorio y las áreas de exposición)

Consecuente con la postura de respeto por el entorno, se opta por la conservación de la fachada sur ya existente, puesto que posee ornamentos armónicos con sus vecinos. De esta forma, para compensar la notoria diferencia de alturas entre la fachada Norte y Sur, se propone un escalonamiento en terrazas, que son utilizadas como jardines florales temáticos para la ejecución del yoga y la meditación, propio en los Havelis indios.

Criterio constructivo y estructural

En cuanto a materialidad se optó por la utilización de hormigón como condición predominante en el proyecto, puesto que éste reinterpreta de manera contemporánea la imagen pétrea característica en la arquitectura tradicional en la India. 
MATERIA PARA LO INTANGIBLE: REMODELACIÓN DE LA VEGA CENTRAL
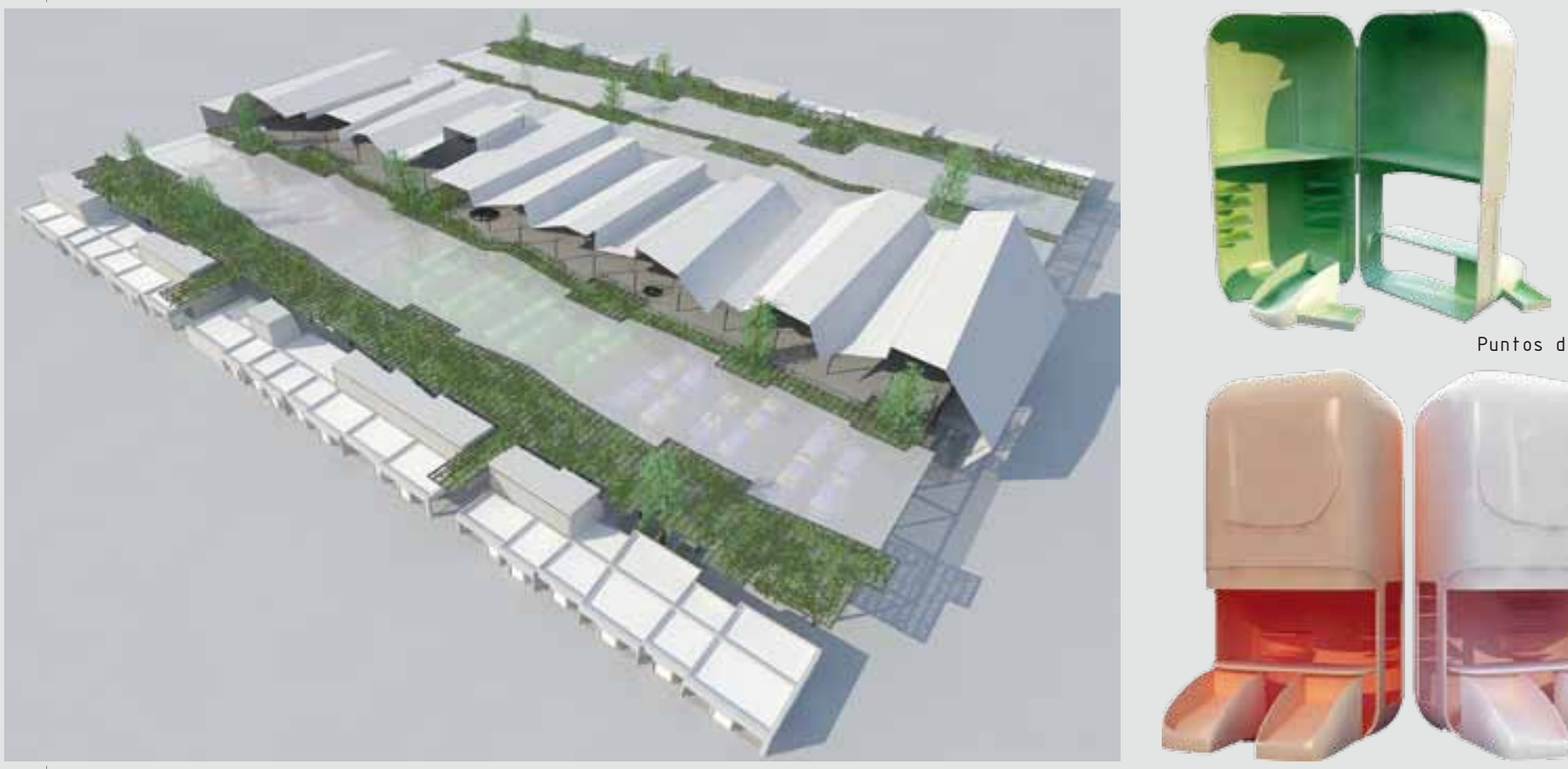

Puntos de venta
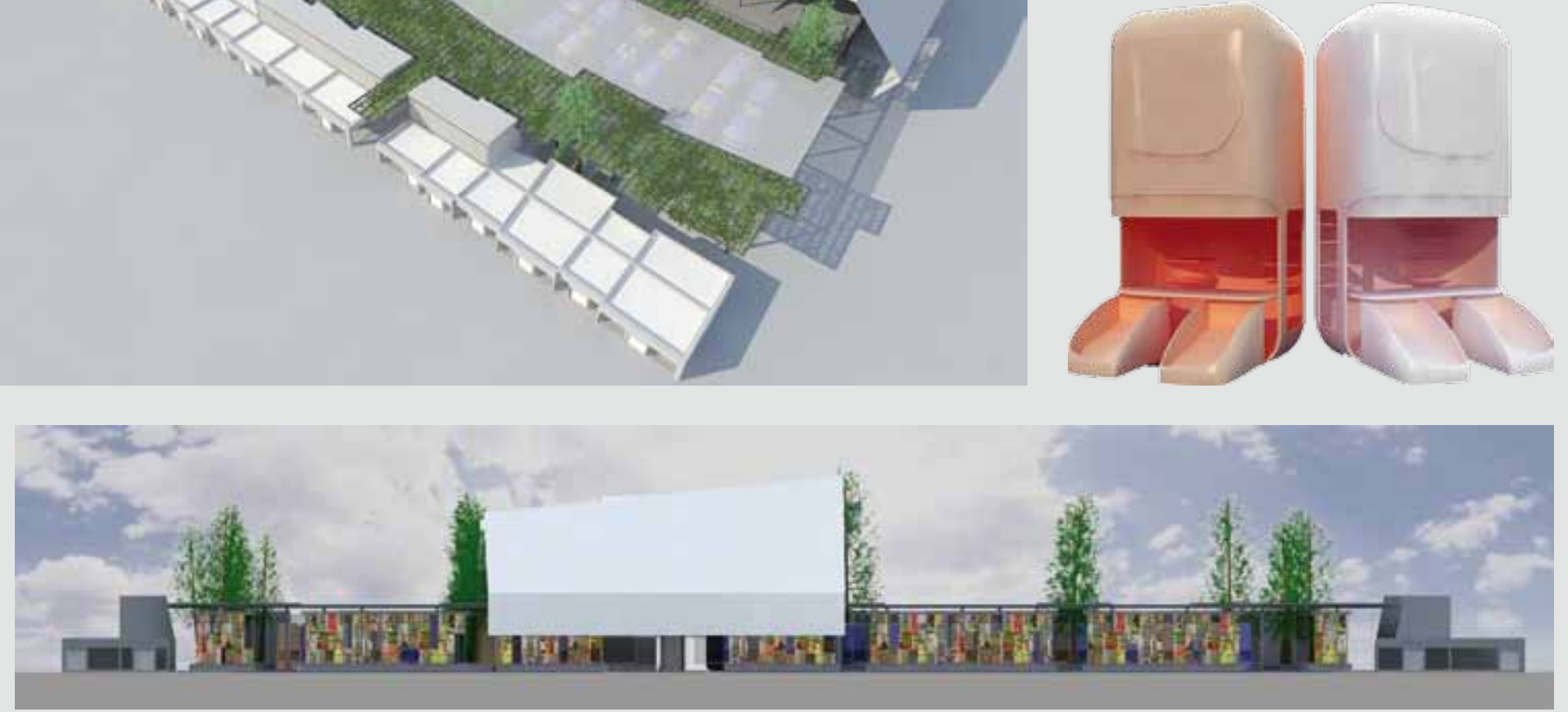

\section{HÉCTOR GÓMEZ R.}

Profesor Guía: Manuel Amaya D.

La Vega Central se ha convertido en un lugar conflictivo para la ciudad. Genera en su entorno: obsolescencia, deterioro, suciedad, delincuencia y congestión vehicular, provocando un dilema sobre mantenerla o desalojarla.

La presión económica ha incitado a los inversionistas a intentar desterrar este emblemático e histórico lugar, a cambio de rentables edificios que no contemplan en ningún sentido, la tradición del entorno. Estas iniciativas se sustentan en que el área no posee valor arquitectónico, ya que sus edificios están en pésimas condiciones y no generan la rentabilidad deseada para un sector tan próximo al centro de la ciudad. Por otra parte, existe la visión romántica de dejar La Vega tal como está ahora. Este punto de vista tampoco ayuda a mejorar la situación, ya que no atiende los problemas actuales.

El proyecto nace a partir de la idea de renovar e implementar infraestructura para la actividad, resguardando su patrimonio intangible, dándole arquitectura (materia) a lo etéreo (actividad y su valor intangible)

Se plantea una solución intermedia que rescata los valores del entorno y la actividad, y a la vez se hace rentable y acorde a las necesidades actuales, logrando una integración a la ciudad y una modernización sin perder su tradición.

El proyecto se integra a la ciudad por medio de contenedores y filtros.

Filtros: nuevas aperturas controladas y clasificadas para el peatón o el vehículo. Incluye estacionamientos subterráneos para descargas de camiones, subasta de productos, bodegaje y todo programa arquitectónico molesto y contaminante.
Mientras que la superficie queda habilitada para el paseo peatonal en áreas verdes (escasas en Santiago)

Contención: Se construye un borde sólido de programa «bisagra» (vivienda, comercio y servicios) que funciona como articulador y límite de la actividad impidiendo que los agentes negativos se desbanden (suciedad, deterioro). Conformando un núcleo blando y flexible donde se emplaza el proyecto.

La actividad se caracteriza por ser flexible, improvisada y pintoresca, es por eso que la propuesta rescata estos valores en la imagen del proyecto (vegetación cambiante en el año, puestos de ventas de colores, carteles publicitarios a modo de fachadas, etc.); la flexibilidad de sus materiales: poliéster reforzado (puestos ensamblables), acero desmontable, telas; y el ordenamiento para controlar su funcionamiento. 
PARQUE INUNDABLE EN SIEM REAP, TEJEDOR DE RELACIONES URBANAS
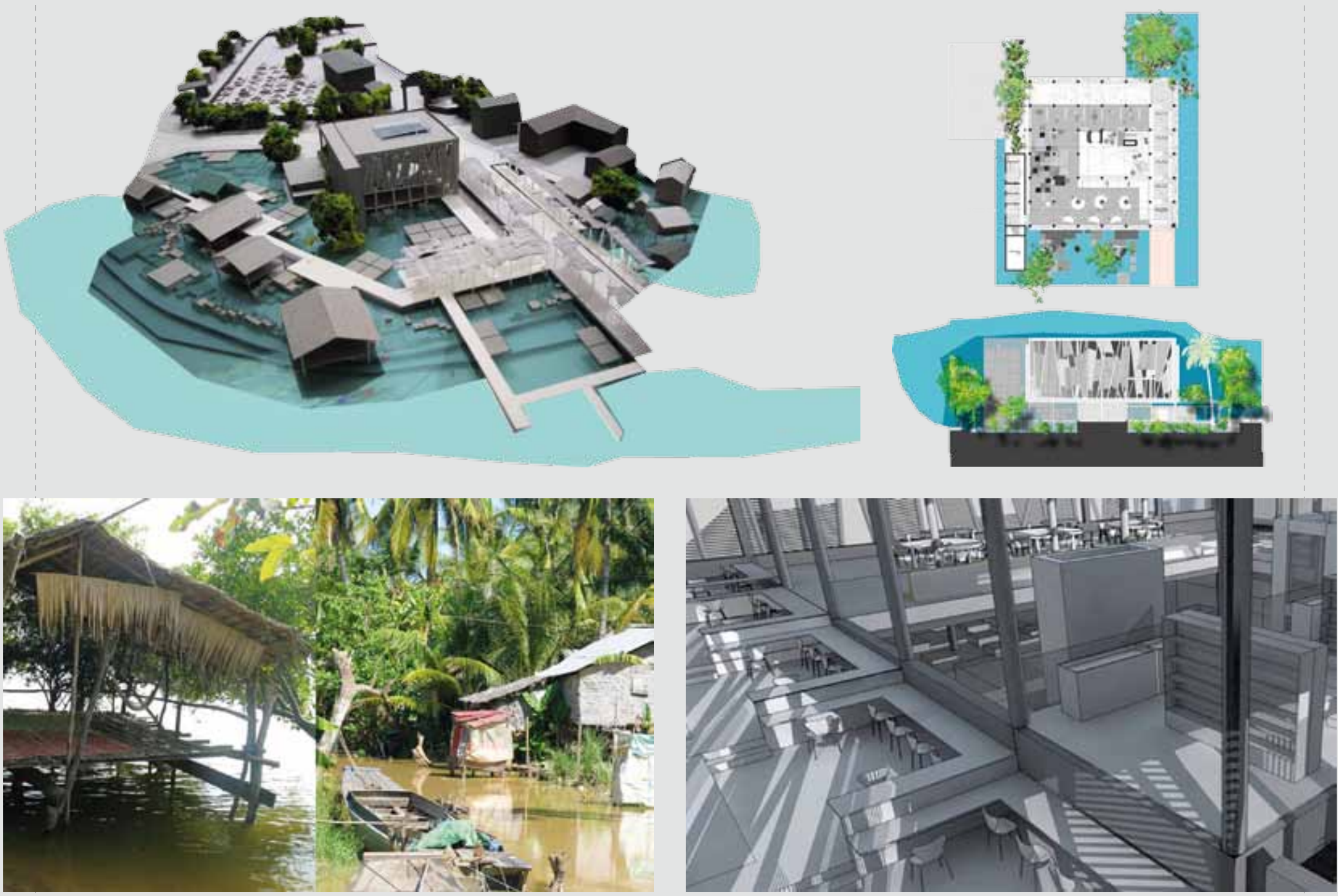

DANIELA MUÑOZ P.

Profesor Guía: Humberto Eliash D.

El proyecto se desarrolla en Siem Reap, Camboya. Por su ubicación geográfica el territorio Camboyano está dominado por el flujo constante de las aguas, condicionando modos y espacios de creación de vida.

La idea de topografía es cambiante y la arquitectura se modifica para recibirla generando neo topografías, naturales humanizadas. (micro topografías).

Siem Reap es el punto medio entre las ruinas de Angkor, patrimonio arqueológico de la humanidad y el lago Tonle Sap, reserva hidráulica de la biosfera que aumenta 4 veces su tamaño en época de monzones, inundado y modificando la percepción espacial del territorio.
Decido trabajar en el centro de Siem Reap, ya que aquí convergen la mayor cantidad de modos de vida presentes en la ciudad, mi terreno es un vacío inundable en el centro, colinda con los elementos identitarios más importantes de la ciudad, pero por su condición de inundable no existe coacción entre ellos.

Mi proyecto apela a entender y reinterpretar la riqueza de los tramados relacionales camboyanos generando un espacio en el que convivan las diferentes realidades de la ciudad, entendiendo el agua como patrimonio, generando un parque inundable con programas que relacionan los elementos del entorno. Un nuevo cluster en la cludad.

Retomo la idea de las micro topografías para generar un nuevo suelo, compuesto por losas de hormigón fijas a distintos niveles (de 0,25 a 1,25 m, inundación máxima) y losas móviles de madera que suben con la inundación. La percepción espacial del terreno cambia según la época del año, permitiendo su ocupación constante.

Retomo los elementos del entorno para generar el programa del parque.

Un puente-muelle que conecta la zona comercial turística con el terreno.

Un puente vehicular peatonal con soporte comercial ligero (tomándome del que ya existe en a zona) y una biblioteca enfrentando a la pagoda, apoyando el programa cultural histórico de la ciudad. 


\section{AMPLIACIÓN Y REMODELACIÓN INSTITUTO NACIONAL DEL CÁNCER}
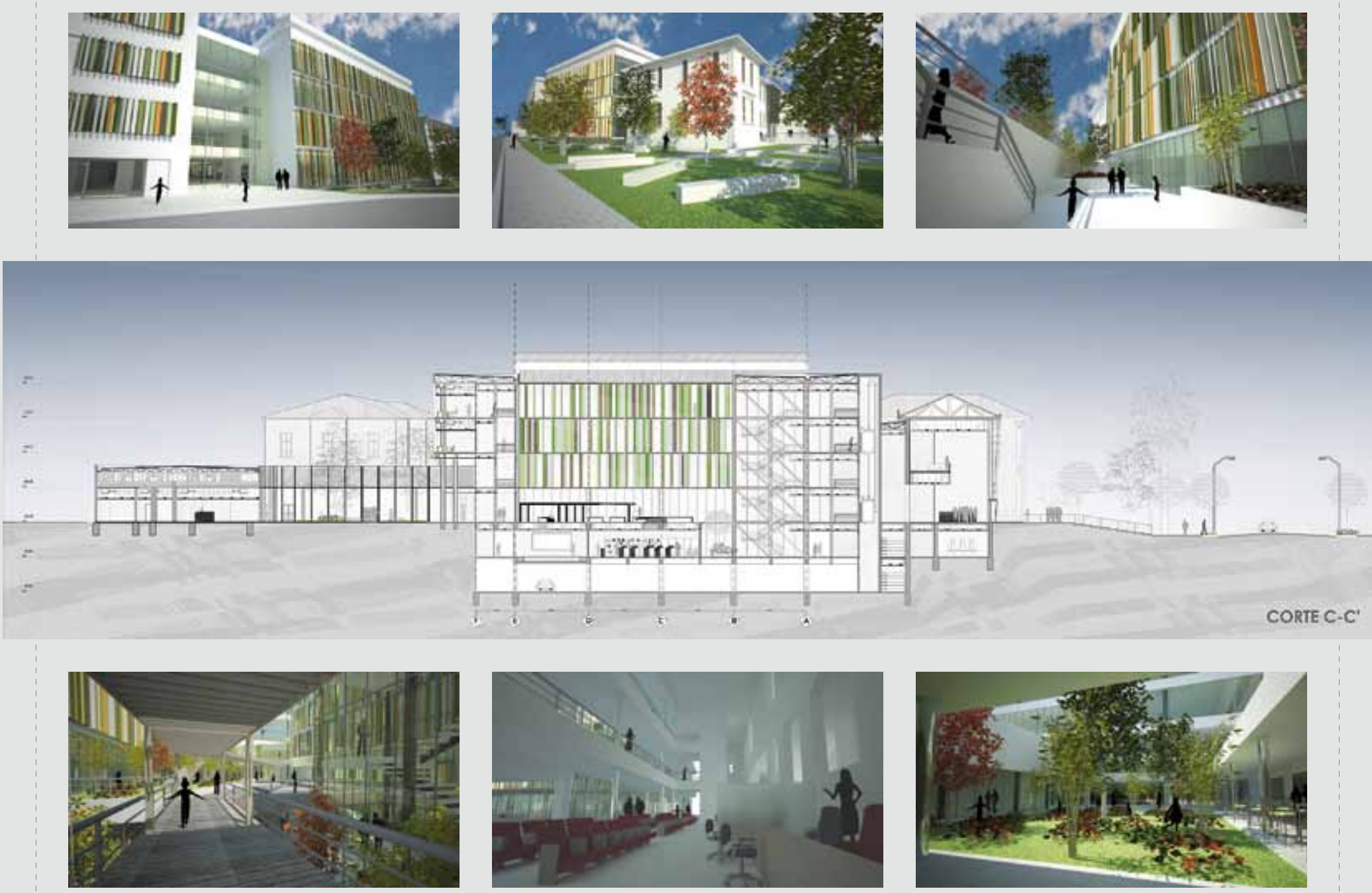

\section{CELSO PUCHI A.}

Profesor Guía: Alberto Montealegre K.

Este proyecto corresponde a la Normalización del Instituto Nacional del Cáncer, considerando construcción nueva fundamentalmente y remodelación o demolición de lo existente. Las condiciones de los edificios existentes presentan severas deficiencias estructurales, de espacialidad y de un programa adecuado para su correcto funcionamiento.

Se concluye utilizar el mismo terreno en el cual funciona actualmente, aprovechando los beneficios de centralidad con respecto a la ciudad y la cercanía con otros centros asistenciales, facilitando el trabajo en red con otros complejos hospitalarios.

La intervención consta de la demolición de las alas más afectadas del antiguo complejo, manteniendo sólo las construcciones factibles de reutilizar.

Para definir los edificios a demoler se tomó en cuenta los siguientes parámetros: valor arquitectónico, y con respecto al conjunto, densidad y costo de su construcción y planta adecuada a su funcionamiento, entre otros factores.

Las nuevas instalaciones albergan los recintos clínicos del hospital y además cumplen un rol unificador del conjunto, manteniendo una relación armónica con las antiguas instalaciones.

Dentro de la configuración del conjunto, se conserva un ordenamiento en torno a un patio central, que al sumarlo a los patios perimetrales, permite una relación directa interior-exterior, entregando a pacientes y funcionarios vistas hacia jardines desde todos los recintos de labores clínicas.
Se decide construir tres edificios funcionales estructuralmente independientes, destinados a atención ambulatoria, pacientes críticos y hospitalización, manteniendo las labores industriales y de apoyo clínico en un piso zócalo comunicado con todos los servicios.

En síntesis, este proyecto busca transformarse en un edificio inteligente que garantiza primero, la operatividad y funcionalidad ante cualquier eventualidad; segundo, la transformación y absorción hacia el interior de readecuaciones a su programa, permitiendo un rango de flexibilidad futura y, como tercera cosa, concertar éstos y otros criterios de diseño en un edificio que colabore en el proceso de sanación de los pacientes enfermos de cáncer. 


\section{ESTACIÓN INSULAR DE INVESTIGACIÓN Y DIFUSIÓN DE LA BIODIVERSIDAD MARINA. ISLA ROBINSON CRUSOE, V REGIÓN}
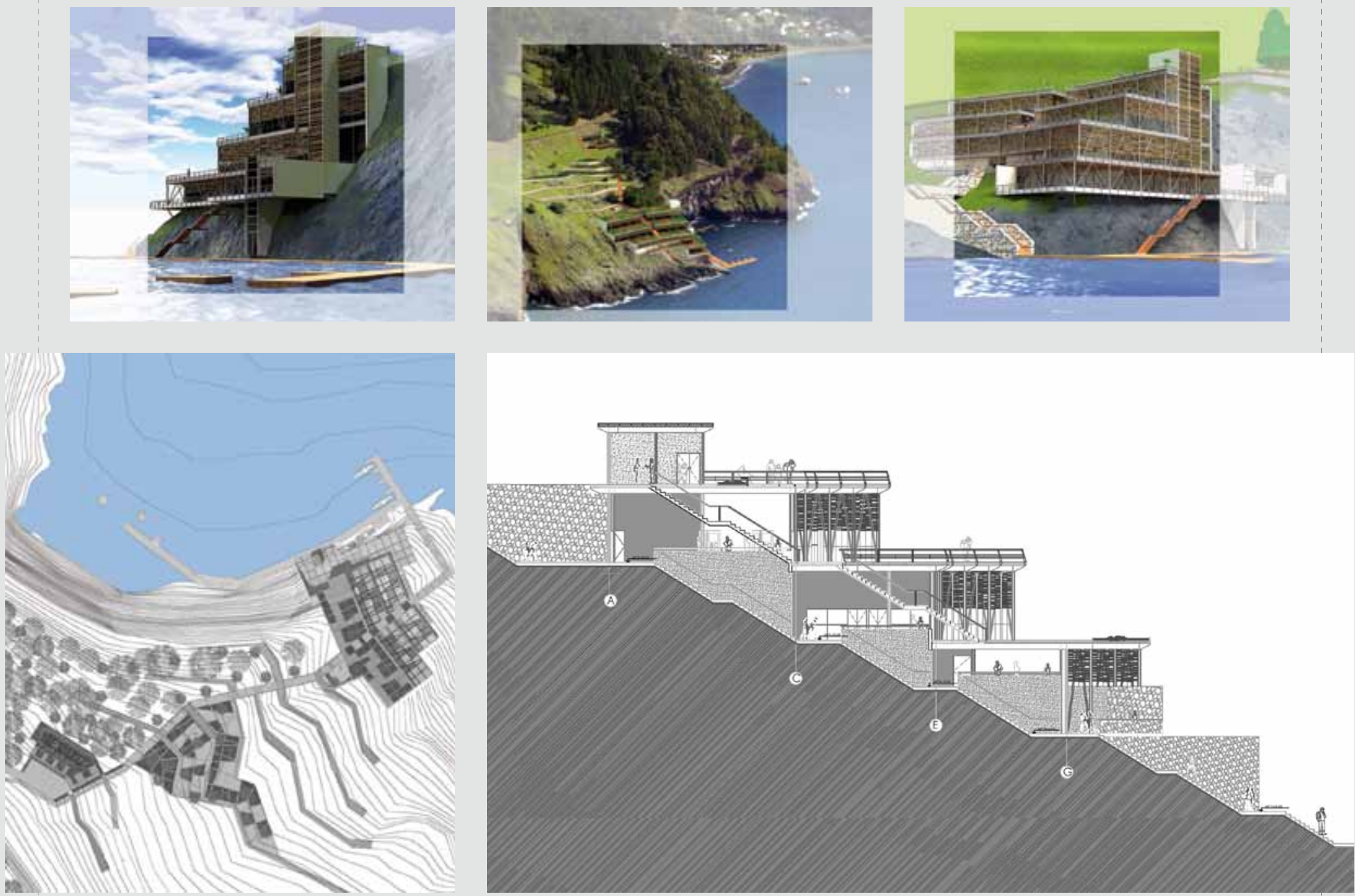

\section{ELIZABETH ESPINOZA M.}

Profesor Guía: Yves Besançon

El proyecto emana del lugar, donde se conjuga un ecosistema único, con recursos naturales potenciables y la necesidad de infraestructura para apoyar el desarrollo sustentable de este patrimonio

El archipiélago Juan Fernández es reconocido internacionalmente por sus atributos naturales de flora y fauna endémicas, siendo declarado Parque Nacional (Gobierno de Chile, 1935) y Reserva Mundial de la Biosfera (UNESCO, 1977). Asimismo, cuenta con un medio oceánico rico en biodiversidad marina, con las condiciones propicias para la exploración, por lo que fue incorporado al Sendero de Chile (CONAMA,
SERNATUR, 2004) como el único tramo submarino, trazado en las costas del centro poblado, en la Isla Robinson Crusoe.

La investigación y difusión marina representan una gran oportunidad para ampliar el conocimiento del medio oceánico, enfocado a la conservación de los recursos de nuestro territorio marítimo. En este ámbito, existen numerosas instituciones dedicadas a las ciencias del mar, sin embargo, el estudio insular ha sido limitado por la falta de infraestructura en terreno.

El terreno escogido se enmarca dentro del límite urbano, al sur poniente de la bahía Cumberland, formando parte del área de proyección del poblado, por lo que el proyecto establecería un nuevo polo de desarrollo hacia esta zona.
El programa establece dos áreas complementarias: la investigación aplicada (en terreno y laboratorios) y la difusión al público general (salas de exposición, biblioteca) y específico (salas de capacitación), tanto local como para visitantes.

El planteamiento arquitectónico surge de la experiencia del lugar, rescatando conceptos del paisaje como la huella y las capas para establecer la conexión tierra-mar, abordando el terreno en forma aterrazada, en un recorrido lineal que va atravesando las distintas plataformas programáticas, desde los recintos secos a los húmedos, desde lo general a lo específico. 


\section{NUEVA ESCUELA SANTA MARÍA DE IQUIQUE}
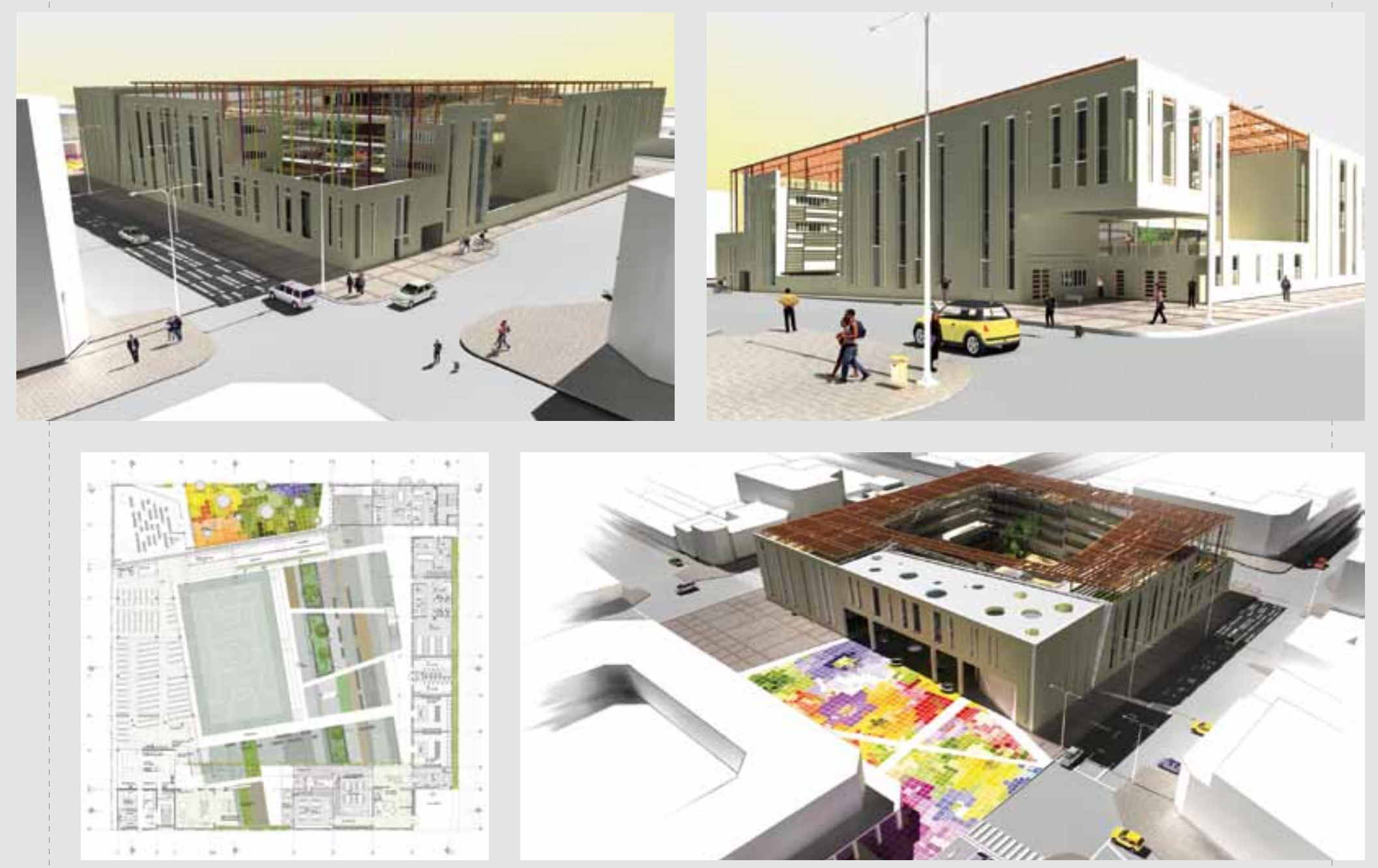

\section{NATALIA FIGUEROA L.}

Profesor Guía: Humberto Eliash D.

En la conmemoración del centenario de la Matanza a los obreros del salitre de la Pampa del Tamarugal, en la escuela Santa María de Iquique el 21 de diciembre de 1907, el lugar se encuentra en lamentables condiciones de abandono y deterioro. Más aún en el 2005 un terremoto en el Norte de nuestro país produce daños estructurales irreparables en el actual edificio de la escuela Santa María, en el centro de Iquique, debiendo ser cerrado y en espera a ser demolido. A 2 años de dicha catástrofe el edificio aún no ha sido repuesto.

El proyecto de la Nueva escuela Santa María de lquique debe responder entonces a 3 elementos que actuarán como las directrices de éste:

1. Al contexto: principalmente al clima desértico litoral en que se emplaza.
2. Al patrimonio cultural que posee la escuela por la significación histórica de los hechos que allí acontecieron.

3. A los requerimientos que la Reforma educacional establece para el diseño de los nuevos espacios educativos.

Se pretende, a través de un único gesto jerárquico, dar respuesta a las 3 variables ya mencionadas. Para ello se propone la utilización del Sol y los juegos de luz y sombra como el elemento unificador y transversal a todas ellas.

El Sol como el elemento característico de los climas desérticos y determinante de las construcciones de dichos lugares (1. contexto). El Sol como elemento cargado de simbolismo y transversal a lugares, culturas y razas, considerando que cerca del $50 \%$ de las víctimas de la matanza fueron extranjeros, entre peruanos, bolivianos y otros (2. Significación histórica). Y el Sol como potencial organizador de programa, debido a lo constante y exacto de su trayectoria solar, el edificio asume un rol activo con su entorno, procurando con ellos la inclusión de la comunidad. (3. Nuevos espacios educativos)

Se propone entonces, un volumen partido, perforado por el Sol, de manera que dicha perforación sea la huella, el recuerdo vigente de la pérdida que significó aquel lamentable hecho. El Sol perfora el volumen y permite a través de dicho gesto que en el interior se genere un mural de luz y sombra, un mural efímero que tendrá lugar cada 21 de diciembre a las 14:45 horas de cada año como homenaje a las familias salitreras que dieron su vida por la esperanza de una vida más justa. 